\title{
ACOUSTICS2008/2213 \\ Thresholds for the perception of fore-and-aft, lateral and vertical vibration by seated persons
}

\author{
M. Morioka and M. J Griffin \\ Institute of Sound and Vibration Research, University of Southampton, Human Factors Research Unit, \\ SO17 1BJ Southampton, UK
}

\begin{abstract}
Vibration experienced in transport and in buildings can yield discomfort or annoyance if the vibration exceeds the threshold for vibration perception. Knowledge of thresholds makes it possible to determine which frequencies and directions of low magnitude vibration give rise to perception. The effect vibration frequency ( 2 to $315 \mathrm{~Hz}$ ) on absolute thresholds for the perception of whole-body vibration has been determined experimentally with 12 seated persons for each of the three axes of excitation (fore-and-aft, lateral and vertical). The frequency-dependence of the thresholds differed between the three axes. At frequencies, greater than 10 $\mathrm{Hz}$, sensitivity was greatest for vertical vibration. At frequencies less than $3.15 \mathrm{~Hz}$, sensitivity was greatest to fore-and-aft vibration. In all three axes, the acceleration threshold contours at frequencies greater than $80 \mathrm{~Hz}$ were U-shaped, suggesting the same psychophysical channel mediated high frequency thresholds for fore-and-aft, lateral and vertical vibration. It is shown that the frequency-dependence of absolute thresholds for the perception of whole-body vibration are not consistent with the frequency weightings used in current standards.
\end{abstract}

Keywords: perception thresholds, whole-body vibration

Technical area: Noise (NS) - Euronoise

PACS \#1: 43.66.Cb Loudness, absolute threshold

PACS \#2: 43.66.Wv Vibration and tactile senses

PACS \#3: 